\title{
Detection of Thrombin Based on Fluorescence Energy Transfer between Semiconducting Polymer Dots and BHQ-Labelled Aptamers
}

\author{
Yizhang Liu ${ }^{1,2, *}$, Xuekai Jiang ${ }^{2}$, Wenfeng Cao ${ }^{2}$, Junyong Sun ${ }^{2}$ and Feng Gao ${ }^{2, *}$ \\ 1 Department of Food and Environmental Engineering, Chuzhou Vocational and Technical College, \\ Chuzhou 239001, China \\ 2 Laboratory of Functionalized Molecular Solids, Ministry of Education, Anhui Key Laboratory of \\ Chemo/Biosensing, Laboratory of Optical Probes and Bioelectrocatalysis (LOPAB), College of Chemistry \\ and Materials Science, Anhui Normal University, Wuhu 241000, China; jiangxuekai@ahnu.edu.cn (X.J.); \\ wfcxi17@mail.ahnu.edu.cn (W.C.); sunjy228@mail.ahnu.edu.cn (J.S.) \\ * Correspondence: liuyizhang111@126.com (Y.L.); fgao@mail.ahnu.edu.cn (F.G.); Tel.: +86-553-3937137 (F.G.)
}

Received: 29 November 2017; Accepted: 6 February 2018; Published: 14 February 2018

\begin{abstract}
Carboxyl-functionalized semiconducting polymer dots (Pdots) were synthesized as an energy donor by the nanoprecipitation method. A black hole quenching dye (BHQ-labelled thrombin aptamers) was used as the energy acceptor, and fluorescence resonance energy transfer between the aptamers and Pdots was used for fluorescence quenching of the Pdots. The addition of thrombin restored the fluorescence intensity. Under the optimized experimental conditions, the fluorescence of the system was restored to the maximum when the concentration of thrombin reached $130 \mathrm{nM}$, with a linear range of $0-50 \mathrm{nM}\left(\mathrm{R}^{2}=0.990\right)$ and a detection limit of $0.33 \mathrm{nM}$. This sensor was less disturbed by impurities, showing good specificity and signal response to thrombin, with good application in actual samples. The detection of human serum showed good linearity in the range of 0-30 nM $\left(\mathrm{R}^{2}=0.997\right)$, with a detection limit of $0.56 \mathrm{nM}$ and a recovery rate of $96.2-104.1 \%$, indicating that this fluorescence sensor can be used for the detection of thrombin content in human serum.
\end{abstract}

Keywords: semiconducting polymer dots; thrombin; aptamer; fluorescence resonance energy trans

\section{Introduction}

As an important physiological protease, thrombin is involved in many physiological and pathological activities, such as blood coagulation, thrombosis and haemostasis [1,2]. The concentration of thrombin varies between the $\mathrm{nM}$ and $\mathrm{mM}$ levels. When a coagulation and anticoagulation imbalance occurs due to injury of the body or disease, the in vivo thrombin activity changes. Thus, quantitative detection of thrombin content for the assessment ofcoagulation ability has important significance in clinical medicine and disease diagnosis [3-5].

The binding between target molecules of nucleic acid aptamers and proteins selected using the technique of systematic evolution of ligands by exponential enrichment (SELEX) is similar to the binding of antibody and antigen. Nucleic acid aptamers can tightly bind to the target molecule, showing advantages of good storage attribute, high specificity, strong affinity, and high selectivity, and have been widely applied in studies to identify the aptamer sensor of different disease-related protein molecules [6-11]. Current photochemical methods for the detection of thrombin content based on aptamers include fluorescence methods [12,13], colorimetric methods [14,15], and Raman scattering [16,17], electrochemical methods include impedance methods [18-21], and polarography [22-24]. Kopelman's group recently reported a new method for the detection of thrombin by magnetic bead rotation [25]. The research group of Gao reported a new thrombin detection method based on a phosphorescence energy transfer system with a detection limit of $0.013 \mathrm{nM}$ [26]. 
In recent years, research on semiconducting polymer dots (Pdots) has received increasing attention from scholars [27-30]. Pdots have excellent optical properties, such as a large optical absorption cross section and high fluorescence quantum yield, and show good biocompatibility and colloidal stability. Pdots are therefore particularly suitable for the design of nanofluorescent probes with high fluorescent brightness and high stability [31-34].

In this study, carboxyl-functionalized Pdots synthesized by nanoprecipitation were used as the energy donors, and BHQ-labelled thrombin aptamers were used as the energy acceptors. The $\pi-\pi$ stacking effect of the aptamers and Pdotsin close proximity produced a resonant energy transfer system, resulting in fluorescence quenching of the Pdots.

Afterthe addition of thrombin, the strong binding of the aptamers to thrombin caused the fluorescence group to move away from the BHQ-thrombin complex, restoring the fluorescence intensity and enabling quantitative determination of thrombin (Figure 1).

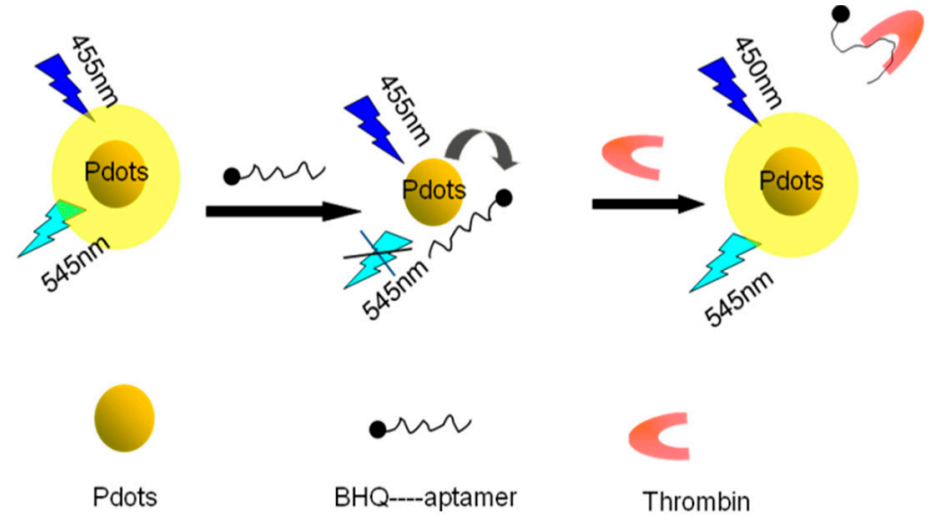

Figure 1. Schematic diagram of the detection of thrombin by high-efficiency energy transfer between functionalized Pdots and black hole quenching dye (BHQ).

\section{Experimental Section}

\subsection{Reagents and Materials}

The experimental equipment in this study includeda UV-vis UV-3010 spectrophotometer (Hitachi, Tokyo, Japan), a digital rotary evaporator (IKA, Staufen im Breisgau, Germany), an ultrasonic cleaner (Branson Ultrasonics, Danbury, CT, USA), an LS-55 fluorescence spectrophotometer (PerkinElmer, Akron, OH, USA), a quartz cuvette $(1 \mathrm{~cm} \times 1 \mathrm{~cm})$, a laser dynamic light scattering (DLS) detector, a thermostatic shaker (Shiping, Shanghai, China), a pHS-3C pH meter (Weiye, Shanghai, China), an H-600 transmission electron microscope (Hitachi, Tokyo, Japan), an analytical balance (Yueping, Shanghai, China), a thermostatic magnetic stirrer (IKA, Staufen im Breisgau, Germany), syringe filters (Sangon Biotech, Shanghai, China), and syringes (Sangon Biotech, Shanghai, China). Luminescence lifetime were carried out on an FLS920 spectrofluorometer (Edinburgh Instruments, Livingston, UK).

The experimental materials in this study included poly[9,9-dioctylfluorenyl-2,7-diyl)-co-1,4-benzo -\{2,10-3\}-thiadiazole)] (PFBT) alternating copolymer and poly[styrene-co-(maleic anhydride)] (PSMA) purchased from ADS, USA, 4-(2-hydroxyethyl)-1-piperazine ethanesulphonic acid (Hepes, Sangon Biotech, Shanghai, China),tetrahydrofuran (THF 99.9\%, Sigma-Aldrich, Saint Louis, MO, USA), ultrapure water and BHQ-labelled thrombin aptamer (5'-GGTTGGTGTGGTTGG-3') (Sangon Biotech Co., Ltd., Shanghai, China).

\subsection{Preparation of Semiconducting Polymer Quantum Dots (Pdots)}

First, $250 \mu \mathrm{L}$ of PFBT solution and $50 \mu \mathrm{L}$ of PSMA solution (stock solutions with a mass concentration of $1 \mathrm{mg} / \mathrm{mL}$ ) were used to prepare a $5 \mathrm{~mL}$ solution in THF, which was mixed thoroughly by ultrasonic vibration. Under ultrasonic vibration, $10 \mathrm{~mL}$ of ultra-pure water was quickly added 
to the solution, and the ultrasonic vibration was continued for 5-6 min. The resulting mixture was heated in a rotary evaporator to remove THF. After filtration and volume adjustment, a Pdots solution of $50 \mathrm{mg} / \mathrm{mL}$ with good water dispersibility was obtained. The preparation was stored in a $4{ }^{\circ} \mathrm{C}$ refrigerator until use [35-37].

\subsection{Interaction between Carboxyl-Functionalized Pdots and BHQ-TBA}

For the reaction, $10 \mu \mathrm{L}$ of $50 \mathrm{mg} / \mathrm{mL}$ Pdots and different amounts of BHQ-TBA were mixed, and the volume was adjusted to $1 \mathrm{~mL}$ with HEPES buffer $(20 \mathrm{mM}, \mathrm{pH} 7.4,140 \mathrm{mM} \mathrm{NaCl})$, followed by culturing in a thermostatic shaker for $1 \mathrm{~h}\left(200 \mathrm{r} / \mathrm{min}, 37^{\circ} \mathrm{C}\right)$. The fluorescence intensity was measured at an excitation wavelength of $455 \mathrm{~nm}$.

\subsection{Detection of Thrombin}

In a colorimetric cuvette containing $10 \mu \mathrm{L}$ of $50 \mathrm{mg} / \mathrm{mL}$ Pdots and an optimal concentration of BHQ-TBA, different concentrations of thrombin were added, and the volume was adjusted to $1 \mathrm{~mL}$ with HEPES buffer, followed by reaction under the same conditions for $1 \mathrm{~h}$. The fluorescence intensity was then measured.

\subsection{Determination of Serum Thrombin}

Serum samples (provided by Hospital of Anhui Normal University, Wuhu, China) were diluted 100-fold with HEPES buffer and subjected to thrombin detection. All other conditions remained unchanged, and the fluorescence intensity was measured.

\section{Results and Discussion}

A functionalized Pdots aqueous solution with good water dispersibility was prepared by the nanoprecipitation method. The UV absorption peak was observed at $455 \mathrm{~nm}$ by UV-VIS spectrophotometry, and the fluorescence emission peak was observed at $545 \mathrm{~nm}$ by fluorescence spectrophotometry (Figure 2a), consistent with findings reported in the literature [38]. On the other hand, Figure $2 b$ shows a image of carboxyl functionalized Pdots. The functionalized Pdots were spherical particles with good water dispersibility, uniform size, a diameter of approximately $30 \mathrm{~nm}$ and no apparent polymerization. Figure 2c shows the particle size distribution of the functionalized Pdots by dynamic light scattering, which demonstrated that the particle size was consistent with the TEM image.

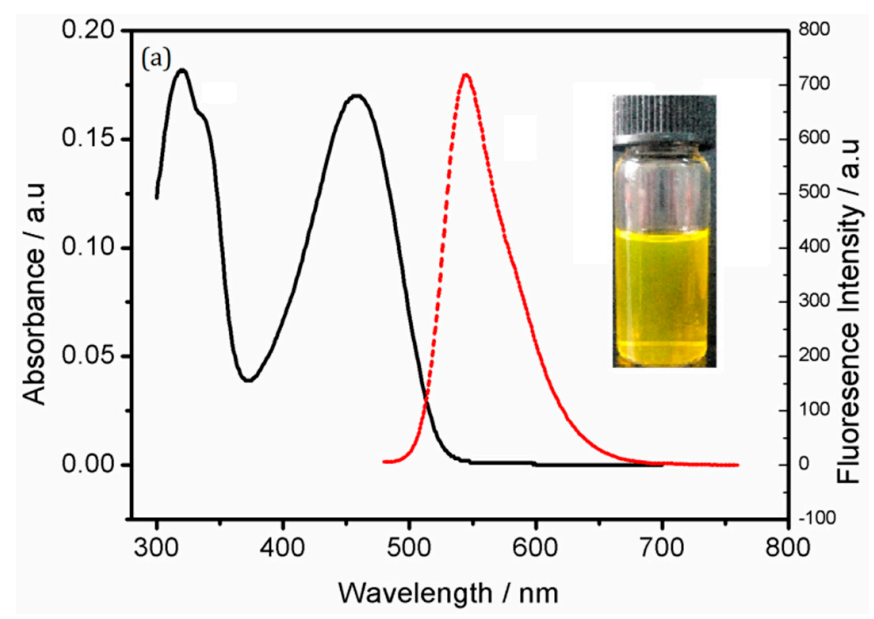

Figure 2. Cont. 

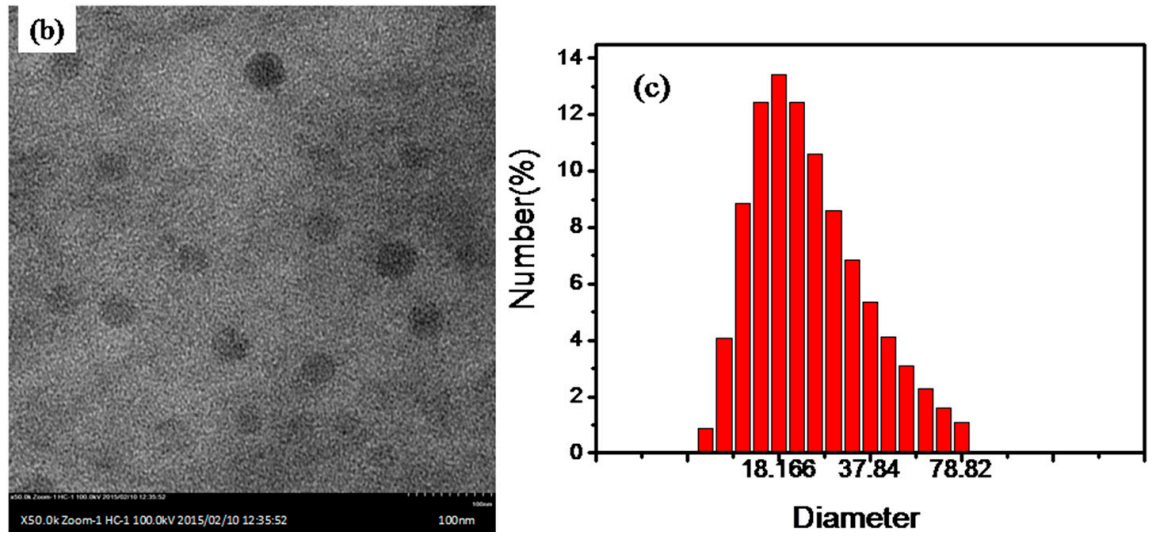

Figure 2. (a) UV-VIS absorption spectrum (solid line), fluorescence emission spectrum (dashed line, excitation at $455 \mathrm{~nm}$ ) of Pdots in HEPES buffer (20 mM, pH 7.4). (b) Image of functionalized Pdots; (c) particle size distribution of functionalized Pdots as determined by dynamic light scattering.

The fluorescence spectrum of the functionalized Pdots and the absorption spectrum of BHQ-TBA greatly overlap, thus enabling energy transfer with fluorescence resonance with the functionalized Pdots as the donors and BHQ-TBA as the receptors. We investigated the degree of fluorescence quenching by adding different concentrations of BHQ-TBA to the functionalized Pdots (Figure 3). Different concentrations of BHQ-TBA solution (from 0.0 to $130 \mathrm{nM}$ ) were added to a solution of $0.5 \mathrm{mg} / \mathrm{mL}$ functionalized Pdots [39].

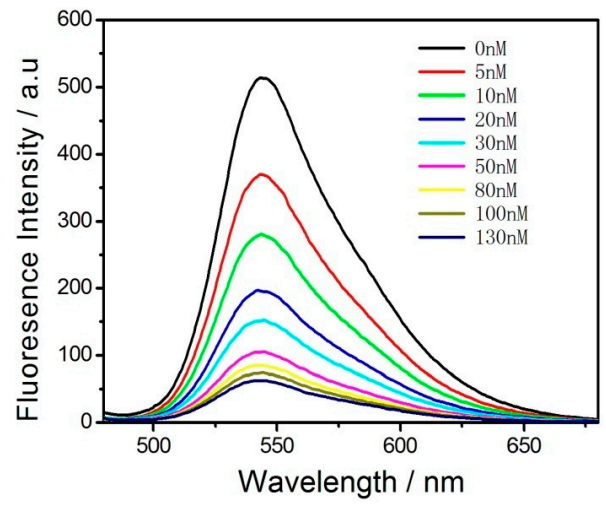

Figure 3. Quenching of fluorescence emission spectra of $0.5 \mathrm{mg} / \mathrm{mL}$ functionalized Pdots upon titration by BHQ-TBA in HEPES buffer (20 mM, pH 7.4). The concentrations of BHQ-TBA were 0, 5, 10, 20, 30, 50, 80, 100 and $130 \mathrm{nM}$. Excitation was performed at $455 \mathrm{~nm}$.

As the concentration of BHQ-TBA increased, the fluorescence intensity of the system gradually decreased. When the concentration of the BHQ-TBA solution reached $130 \mathrm{nM}$, the quenching reached a maximum. When a solution of BHQ-TBA was added to the functionalized Pdot solution, the $\pi-\pi$ stacking effect between BHQ-TBA and the Pdots in close proximity formed a resonance energy transfer system, thereby quenching the fluorescence of the Pdots. The quenching efficiency was calculated as $\left(1-F / F_{0}\right)$, in which $F_{0}$ and $F$ represent the fluorescence intensities of the functionalized Pdots in the absence $\left(F_{0}\right)$ and presence $(F)$ of the BHQ-TBA solution (Figure S1). When $130 \mathrm{nM}$ BHQ-TBA solution was added to the system, the quenching efficiency was calculated to be $88.7 \%$, indicating that BHQ-TBA had a strong ability to quench the functionalized Pdots, laying the foundation for the design of a sensitive "turn-on" mode sensor. Meanwhile, the impact of BHQ-TBA reaction time on the fluorescence intensity of the functionalized Pdots solution is shown in Figure S2. The fluorescence intensity reached a minimal value in approximately $50 \mathrm{~min}$. To ensure the stability of the fluorescence signal, the optimal incubation time was set at $60 \mathrm{~min}$. 
To further confirm the FRET mechanism between Pdots and BHQ-TBA, time-resolved fluorescence measurements were performed by collecting the emission intensities at $545 \mathrm{~nm}$. Figure S5 shows the fluorescence lifetime is estimated to be 1.09 ns for Pdots-BHQ-TBA and $0.97 \mathrm{~ns}$ for Pdots, respectively.

The response of the functionalized Pdots-BHQ-TBA fluorescence energy transfer system to thrombin was investigated. As shown in Figure 4, Upon $20 \mathrm{nM}$ thrombin was added to $0.5 \mathrm{mg} / \mathrm{mL}$ functionalized Pdots, the fluorescence of the system did not change significantly (curve b). With the addition of $130 \mathrm{nM}$ BHQ-TBA solution, the fluorescence decreased to a minimum (curve c), and the addition of $20 \mathrm{nM}$ thrombin to this system partially restored the fluorescence intensity of the system (curve d). The results demonstrated that after adding thrombin to the system, the ability to form the G-quadruplex structure by specific binding between BHQ-TBA and thrombin was much greater than the $\pi-\pi$ stacking effect of BHQ-TBA and functionalized Pdots. Thus, the energy receptor BHQ-TBA bound thrombin and was released from the surface of the energy donor, resulting in the recovery of the fluorescence intensity of the energy donor. To ensure the result and obtain stable signal, a series of seven duplicate measurements was used for estimating the precision, the average of a number of measurements was chosen.

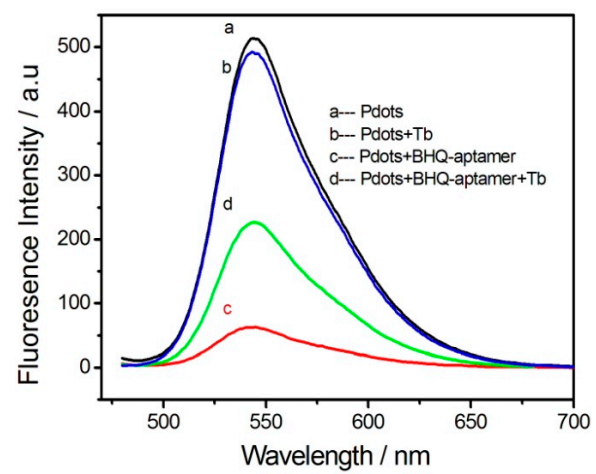

Figure 4. Fluorescence emission spectra of functionalized Pdots in HEPES buffer (20 mM, pH 7.4) upon addition of BHQ-TBA, thrombin. (a) $0.5 \mathrm{mg} / \mathrm{mL}$ functionalized Pdots; (b) $0.5 \mathrm{mg} / \mathrm{mL}$ functionalized Pdots after adding $20 \mathrm{nmol} / \mathrm{L}$ thrombin; (c) $0.5 \mathrm{mg} / \mathrm{mL}$ functionalized Pdots after adding $130 \mathrm{nM}$ BHQ-TBA; (d) The functionalized Pdots-BHQ-TBA system after adding $20 \mathrm{nM}$ thrombin in HEPES buffer. Excitation was performed at $455 \mathrm{~nm}$.

Based on this principle of fluorescence recovery, a new method was established to detect the content of thrombin using "turn-on" fluorescence energy transfer. The recovery of fluorescence intensity when different concentrations of thrombin were added to the Pdots-BHQ-TBA system under the optimized experimental conditions is shown in Figure 5. To ensure the result and obtain stable signal, a series of seven duplicate measurements was used for estimating the precision, the average of a number of measurements was chosen.

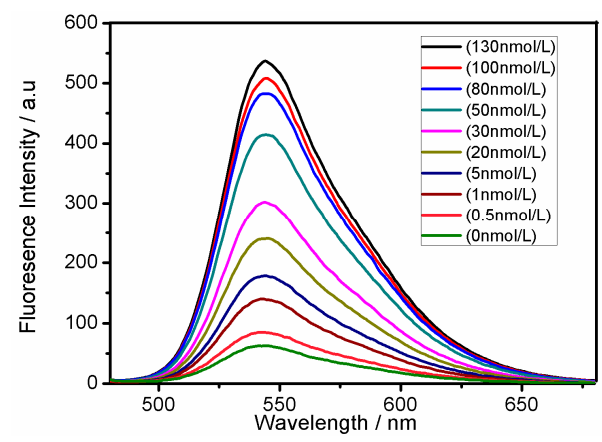

Figure 5. Changing of fluorescence emission spectra of thefunctionalized Pdots-BHQ-TBA system upon titration by thrombin: 0, 0.5, 1, 5, 20, 30, 50, 80, 100, and $130 \mathrm{nM}$ in HEPES buffer (20 mM, pH 7.4). Excitation was performed at $455 \mathrm{~nm}$. 
As the thrombin concentration increased, the fluorescence intensity of the system gradually recovered. When the concentration of thrombin was $130 \mathrm{nM}$, the fluorescence of the system was recovered to the maximum, and increasing the concentration of thrombin did not increase the fluorescence of the system. Based on the definition of $\left(F-F_{0}\right) / F_{0}$ ( $F$ refers to the fluorescence intensity after adding different concentrations of thrombin, and $F_{0}$ refers to the fluorescence intensity with no addition of thrombin), Figure S3 shows the linear relationship between the fluorescence recovery $\left(F-F_{0}\right) / F_{0}$ and the thrombin concentration. When the concentration of thrombin was in the range of 0-50 nM, a good linear relationship was observed $\left(\mathrm{R}^{2}=0.990\right)$. The equation of the standard curve was $\left(F-F_{0}\right) / F_{0}=0.7899+0.0621 \mathrm{c}(\mathrm{c}$ is in $\mathrm{nM})$. The detection limit was $0.33 \mathrm{nM}(\mathrm{S} / \mathrm{N}=3)$. Based on the detection for $20 \mathrm{nM}$ thrombin and the standard deviation of seven repeat measurements, the relative standard deviation of this method was $4.01 \%$, indicating that the detection of thrombin by fluorescence energy transfer in the Pdots-BHQ-TBA system was reproducible. A comparison with other methods is shown in Table 1.

Table 1. Comparison of performances of aptamer-based sensors for thrombin detection.

\begin{tabular}{|c|c|c|c|c|}
\hline Methods & Signal Output/Reporter & $\begin{array}{l}\text { Linear Range } \\
(\mathrm{nmol} / \mathrm{L})\end{array}$ & $\begin{array}{c}\text { Detection } \\
\text { Limit (nmol/L) }\end{array}$ & Ref. \\
\hline $\begin{array}{l}\text { a DNA cycle amplified method based } \\
\text { on ECL quenching of } \mathrm{Fe}_{3} \mathrm{O}_{4} @ \mathrm{CdSe} \\
\text { QDs by gold NPs }\end{array}$ & $\mathrm{ECL} / \mathrm{Fe}_{3} \mathrm{O}_{4} @ \mathrm{CdSe}$ & $0.001-5.0$ & 0.00012 & [39] \\
\hline $\begin{array}{c}\text { turn-On Fluorescence Sensor Based } \\
\text { on single walled carbon } \\
\text { nanohorn-Peptide complex }\end{array}$ & fluorescence/fluorescein & - & 0.1 & [40] \\
\hline $\begin{array}{l}\text { a fluorescence detection based on } \\
\text { simultaneous electrostatic repulsion } \\
\text { and } \pi-\pi \text { stacking interactions of } \\
\text { carboxylic carbon nanoparticles with } \\
\text { single-stranded DNA }\end{array}$ & fluorescence/fluorescein & $0-120$ & 5 & [41] \\
\hline $\begin{array}{l}\text { a aptamer biosensor based on FRET } \\
\text { from upconverting fluorophors to } \\
\text { carbon nanoparticles }\end{array}$ & fluorescence $/ \mathrm{Yb}, \mathrm{Er}, \mathrm{NaYF}_{4}$ & $0.5-20$ & 0.18 & [42] \\
\hline $\begin{array}{l}\text { FRET aptasensor based on the dye } \\
\text { labeled aptamer assembled graphene }\end{array}$ & fluorescence/fluorescein amidite & $0.0625-0.1875$ & 0.0313 & [43] \\
\hline $\begin{array}{l}\text { an electrochemical biosensor based on } \\
\text { switching structure of aptamers from } \\
\text { DNA/DNA duplex to } \\
\text { DNA/target complex }\end{array}$ & current/methylene blue & $6-60$ & 3 & [44] \\
\hline $\begin{array}{l}\text { the combination of LSPR with RRI } \\
\text { spectrum of the gold-capped oxide } \\
\text { nanostructure }\end{array}$ & $\begin{array}{l}\text { RRI/gold-capped oxide } \\
\text { nanostructure }\end{array}$ & $0.001-100,000$ & 1 & [45] \\
\hline $\begin{array}{l}\text { aptamer-based turn-on } \\
\text { fluorescent detection }\end{array}$ & fluorescence/TASPI & $0-2500$ & 50 & [46] \\
\hline $\begin{array}{l}\text { PET-based aptamer sensor } \\
\text { for thrombin }\end{array}$ & Phosphorescence/Mn-ZnS QDs & $0-40$ & 0.013 & [26] \\
\hline This study & Flurorescence/PFBT Pdots & $0-50$ & 0.33 & \\
\hline
\end{tabular}

The impacts of the corresponding ions and similar proteins on the sensor under the same experimental conditions were investigated. Figure 6 shows the fluorescence recovery of the different substances, represented by $F / F_{0}$. Except for $100 \mathrm{nM} B S A$ and $130 \mathrm{nM}$ thrombin, all substances were used at a concentration of $1 \mu \mathrm{M}$. Specific concentrations of the interfering substances were added to the Pdots-BHQ-aptamer system. As shown in Figure 6, the relative fluorescence intensity of the sensor after adding $130 \mathrm{nM}$ thrombin solution was $F / F_{0}=6.5\left(F_{0}\right.$ refers to the fluorescence intensity of the Pdots-BHQ-aptamer system without adding any substance, and $F$ refers to the fluorescence intensity of the system after adding thrombin and the relevant interfering substance). In contrast to the addition of interfering substances, the addition of thrombin solution significantly restored the fluorescence of the system. The impact of other interfering substances was negligible, and thrombin was specifically detected, confirming that thrombin solution can be detected with the "turn-on" fluorescence method. 


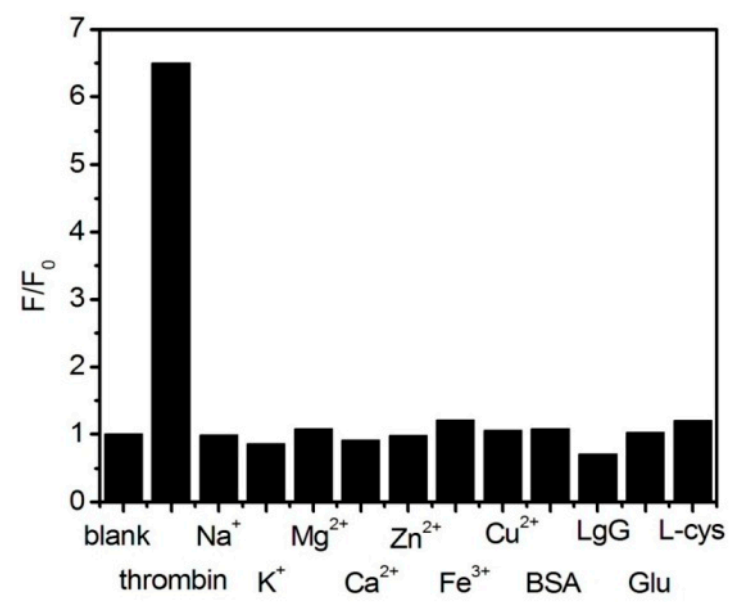

Figure 6. Fluorescence recovery of different substances in HEPES buffer (20 mM, pH 7.4). The concentration of all substances was $1 \mu \mathrm{M}$. $\mathrm{F}_{0}$ is fluorescence intensity at $545 \mathrm{~nm}$ for Pdots-BHQ-TBA, and $\mathrm{F}$ is the fluorescent intensity after adding different substances. Excitation was performed at $455 \mathrm{~nm}$.

To verify the good sensitivity and specificity of this method for the detection of actual samples, the content of thrombin in serum was quantitatively detected. The serum used in the experiment was collected from healthy people. Before use, the sample to be tested was diluted 10-fold with HEPES buffer, and the concentrations of thrombin in the sample and after the addition of the standard were detected. Figure 7 shows the recovery of fluorescence intensity when thrombin at different concentrations was added to human serum under the optimized experimental conditions. The concentrations of thrombin of human serum were determined as $0.45 \mathrm{nM}$, respectively, using the calibration curve obtained in the human serum matrix, which are consistent with the reported levels [40]. As the concentration of thrombin increased, the fluorescence intensity of the system also slowly recovered. As shown in Figure S4, the linearity of the response to thrombin in the concentration range of $0-30 \mathrm{nM}$ was examined, with a good linear relationship in the thrombin concentration range of $0-30 \mathrm{nM}\left(\mathrm{R}^{2}=0.996\right)$. The linear equation was $\left(F / F_{0}\right) / F_{0}=0.6933+0.0829 \mathrm{c}(\mathrm{c}$ is in $\mathrm{nM})$. Compared to the sensor in pure buffer, the sensitivity of the sensor for the detection of thrombin in serum was slightly lower. This may be the result of other factors in the serum. The detection limit was $0.58 \mathrm{nM}(\mathrm{S} / \mathrm{N}=3)$. Based on the detection of $5 \mathrm{nM}$ thrombin and the standard deviation of seven repeat measurements, the relative standard deviation of this method was $4.7 \%$, indicating that the detection of thrombin by fluorescence energy transfer in the Pdots-BHQ-aptamer system was reproducible. To ensure the result and obtain stable signal, a series of seven duplicate measurements was used for estimating the precision, the average of a number of measurements was chosen.

For detection in actual serum samples, thrombin at concentrations of 5.0, 10.0, and $20.0 \mathrm{nM}$ were added to a 10-fold diluted serum sample, and then, the thrombin in the sample was detected by the standard addition method under optimized conditions. The different fluorescence recovery intensities obtained are shown in Table 2. Under the optimized conditions, the standard addition method was used to detect these samples. The recovery rate ranged from $96.2 \%$ to $104.1 \%$, indicating that the fluorescence sensor can be used to detect the content of thrombin in human serum. Therefore, quantitative thrombin assay was achieved in actual serum. In one word, as a brand new analytical method, Pdots FRET has already shown its potential in bioanalytical chemistry. Moreover, there is no doubt that the analytical performances including the detection sensitivity can be further improved in future studies, through the optimization of the properties of probe as well as detection conditions. 


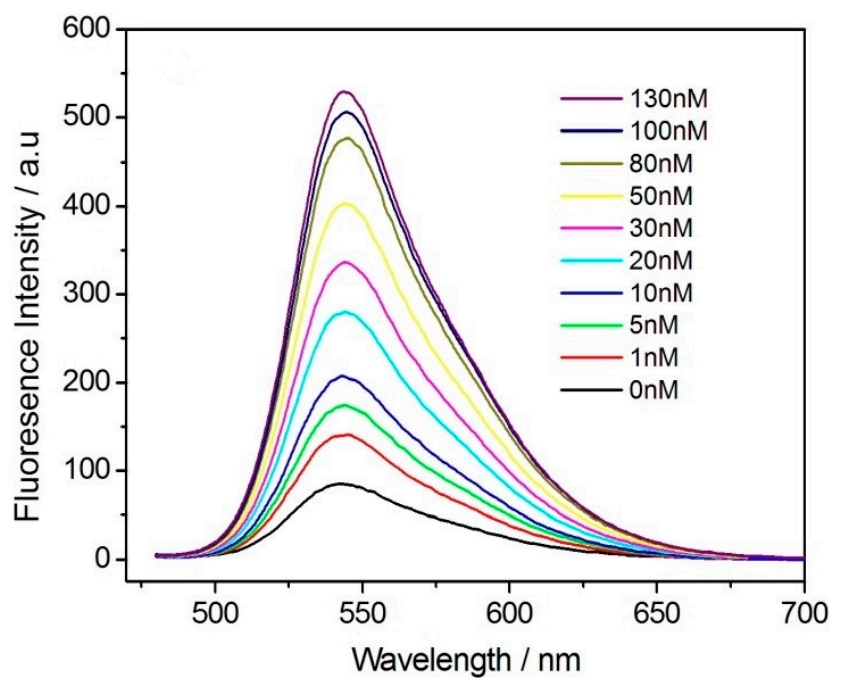

Figure 7. Changing of fluorescence emission spectra of the functionalized Pdots-BHQ-TBA system upon titration by thrombin to serum: $0,1,5,10,20,30,50,80,100$, and $130 \mathrm{nM}$ in HEPES buffer (20 $\mathrm{mM}, \mathrm{pH}$ 7.4). Excitation was performed at $455 \mathrm{~nm}$.

Table 2. Detection of actual samples $(n=6)$.

\begin{tabular}{cccc}
\hline Sample & Spiked $(\mathbf{n m o l} / \mathbf{L})$ & Found $(\mathbf{n m o l} / \mathbf{L} \pm$ SD) & Recovery (\%) \\
\hline 1 & 5.0 & $4.81 \pm 0.02$ & $96.2 \pm 0.4$ \\
2 & 10.0 & $10.41 \pm 0.03$ & $104.1 \pm 0.3$ \\
3 & 20.0 & $20.33 \pm 0.04$ & $101.7 \pm 0.2$ \\
\hline
\end{tabular}

\section{Conclusions}

In conclusion, the principle of fluorescence energy transfer was used for the sensitive quantitative detection of in vivo thrombin content, and a good response in the detection of actual samples (human serum) was confirmed. With functionalized Pdots as the energy donor and BHQ-TBA as the energy receptor, a fluorescence energy transfer system was established. Fluorescence recovery of the system was achieved by specific binding between BHQ-TBA and thrombin to form a G-quadruplex structure. A new method for the detection of thrombin by "turn-on" fluorescence energy transfer was established. The detection limit was $0.33 \mathrm{nM}$. The high fluorescent brightness and high stability of Pdots makes them a promising energy donor for FRET assay in complex biological samples, which will contribute to FRET technique as well as FRET-based analytical applications. Owing to the facile fabrication, the sensor could be readily developed to build up sensing platforms for various targets by linking different aptamers or other ligands to Pdots. Further studies looking into the energy transfer mechanism between Pdots and material would be desired to gain more comprehensive understanding and better applications.

Supplementary Materials: The following are available online at www.mdpi.com/xxx/s1.

Acknowledgments: Yizhang Liu gives deep thanks for financial support (KJ2016SD45) from Anhui Provincial Education Department, and Feng Gao et al. also give deep thanks for financial support by the Natural Science Foundation of China (No. 21575004; 21605001), Program for New Century Excellent Talents in University (NCET-12-0599), the project sponsored by SRF for ROCS, SEM, and the Foundation for Innovation Team of Bioanalytical Chemistry of Anhui Province.

Author Contributions: Feng Gao conceived and designed the experiments; Yizhang Liu performed the experiments; Wenfeng Cao analyzed the data; Junyong Sun contributed reagents/materials/analysis tools; Xuekai Jiang wrote the paper.

Conflicts of Interest: The authors declare no conflict of interest. 


\section{References}

1. Tian, R.; Chen, X.; Li, Q.; Yao, C. An electrochemical aptasensor electrocatalyst for detection of thrombin. Anal. Biochem. 2016, 500, 73-79. [CrossRef] [PubMed]

2. Shuman, M.A.; Majerus, P.W. The measurement of thrombin in clotting blood by radioimmunoassay. J. Clin. Investig. 1976, 58, 1249-1258. [CrossRef] [PubMed]

3. Chen, L.Y.; Bao, Y.G.; Denstedt, J.; Zhang, J. Nanostructured bioluminescent sensor for rapidly detecting thrombin. Biosens. Bioelectron. 2016, 77, 83-89. [CrossRef] [PubMed]

4. Stone, S.R.; Betz, A.; Hofsteenge, J. Mechanistic studies on thrombin catalysis. Biochemistry 1991, 30, 9841-9848. [CrossRef] [PubMed]

5. Lamy, F.; David, F.W. Transformation of prothrombin into thrombin. Phys. Rev. 1954, 34, 722-729. [CrossRef] [PubMed]

6. Jie, G.F.; Chen, K.; Wang, X.C.; Lu, Z.K. Dual-stabilizer-capped CdSe quantum dots for “Off-On” electrochemiluminescence biosensing of thrombin by target-triggered multiple amplification. RSC Adv. 2016, 6, 2065-2071. [CrossRef]

7. German, I.; Buchanan, D.D.; Kennedy, R.T. Aptamers as ligands in affinity probe capillary electrophoresis. Anal. Chem. 1998, 70, 4540-4545. [CrossRef] [PubMed]

8. Zhang, Y.; Ren, W.; Luo, H.Q.; Li, N.B. Label-free cascade amplification strategy for sensitive visual detection of thrombin based on target-triggered hybridization chain reaction-mediated in situ generation of DNA zymes and Pt nanochains. Biosens. Bioelectron. 2016, 80, 463-470. [CrossRef] [PubMed]

9. O'Sullivan, C. Aptasensors-the future of biosensing. Anal. Bioanal. Chem. 2002, 372, 44-48. [CrossRef] [PubMed]

10. Trapaidze, A.; Hérault, J.P.; Herbert, J.M.; Bancaud, A.; Gué, A.M. Investigation of the selectivity of thrombin-binding aptamers for thrombin titration in murine plasma. Biosens. Bioelectron. 2016, 78, 58-66. [CrossRef] [PubMed]

11. Tombelli, S.; Minunni, M.; Mascini, M. Analytical applications of aptamers. Biosens. Bioelectron. 2005, 20, 2424-2434. [CrossRef] [PubMed]

12. Wang, G.L.; Hu, X.L.; Wu, X.M.; Dong, Y.M.; Li, Z.J. Fluorescent aptamer-based assay for thrombin with large signal amplification using peroxidase mimetics. Microchim. Acta 2016, 183, 765-771. [CrossRef]

13. McCauley, T.G.; Hamaguchi, N.; Stanton, M. Aptamer-based biosensor arrays for detection and quantification of biological macromolecules. Anal. Biochem. 2003, 319, 244-250. [CrossRef]

14. Zhang, L.P.; Li, L. Colorimetric thrombin assay using aptamer-functionalized gold nanoparticles acting as a peroxidase mimetic. Microchim. Acta 2016, 183, 485-490. [CrossRef]

15. So, H.M.; Won, K.; Kim, Y.H.; Kim, B.K.; Ryu, B.H.; Na, P.S.; Kim, H.; Lee, J.O. Single-walled carbon nanotube biosensors using aptamers as molecular recognition elements. J. Am. Chem. Soc. 2005, 127, 11906-11907. [CrossRef] [PubMed]

16. Hu, J.; Zheng, P.C.; Jiang, J.H.; Shen, G.L.; Yu, R.Q.; Liu, G.K. Electrostatic interaction based approach to thrombin detection by surface-enhanced Raman spectroscopy. Anal. Chem. 2008, 81, 87-93. [CrossRef] [PubMed]

17. Xiao, Y.; Lubin, A.A.; Heeger, A.J.; Plaxco, K.W. Label-free electronic detection of thrombin in blood serum by using an aptamer-based sensor. Angew. Chem. 2005, 44, 5456-5459. [CrossRef] [PubMed]

18. Derkus, B.; Arslan, Y.E.; Bayrac, A.T.; Kantarcioglu, I.; Emregul, K.C.; Emregul, E. Development of a novel aptasensor using jellyfish collagen as matrix and thrombin detection in blood samples obtained from patients with various neurodisease. Sens. Actuators B 2016, 228, 725-736. [CrossRef]

19. Numnuam, A.; Chumbimuni-Torres, K.Y.; Xiang, Y.; Bash, R.; Thavarungkul, P.; Kanatharana, P.; Pretsch, E.; Wang, J.; Bakker, E. Aptamer-Based Potentiometric Measurements of Proteins Using Ion-Selective Microelectrodes. Anal. Chem. 2008, 80, 707-712. [CrossRef] [PubMed]

20. Wang, Y.G.; Zhang, Y.; Yan, T.; Fan, D.W.; Du, B.; Ma, H.M.; Wei, Q. Ultrasensitive electrochemical aptasensor for the detection of thrombin based on dual signal amplification strategy of Au@GS and DNA-CoPd NPs conjugates. Biosens. Bioelectron. 2016, 80, 640-646. [CrossRef] [PubMed]

21. Radi, A.E.; Sanchez, J.L.A.; Baldrich, E.; Sullivan, C.K.O. Reagentless, reusable, ultrasensitive electrochemical molecular beacon aptasensor. J. Am. Chem. Soc. 2006, 128, 117-124. [CrossRef] [PubMed] 
22. Erdem, A.; Congur, G.; Mayer, G. Aptasensor platform based on carbon nanofibers enriched screen printed electrodes for impedimetric detection of thrombin. J. Electroanal. Chem. 2015, 758, 12-19. [CrossRef]

23. Rahman, A.; Song, J.I.; Won, M.S.; Shim, Y.B. Gold nanoparticles doped conducting polymer nanorod electrodes: ferrocene catalyzed aptamer-based thrombin immunosensor. Anal. Chem. 2009, 81, 6604-6611. [CrossRef] [PubMed]

24. Wen, Q.Q.; Lu, P.; Yang, P.H. A glassy carbon electrode modified with in-situ generated chromium-loaded CdS nanoprobes and heparin for ultrasensitive electro chemiluminescent determination of thrombin. Microchim. Acta 2016, 183, 123-132. [CrossRef]

25. Hecht, A.; Kumar, A.A.; Kopelman, R. Label-acquired magnetorotation as a signal transduction method for protein detection: aptamer-based detection of thrombin. Anal. Chem. 2011, 83, 7123-7128. [CrossRef] [PubMed]

26. Zhang, L.; Cui, P.; Zhang, B.C.; Gao, F. Aptamer-based turn-on detection of thrombin in biological fluids based on efficient phosphorescence energy transfer from Mn-doped ZnS quantum dots to carbon nanodots. Chem. Eur. J. 2013, 19, 9242-9250. [CrossRef] [PubMed]

27. Li, S.Y.; Chang, K.W.; Sun, K.; Tang, Y.; Cui, N.; Wang, Y.; Qin, W.P.; Xu, H.; Wu, C.F. Amplified Singlet Oxygen Generation in Semiconductor Polymer Dots for Photodynamic Cancer Therapy. ACS Appl. Mater. Interfaces 2016, 8, 3624-3634. [CrossRef] [PubMed]

28. Zhang, D.; Wu, M.; Zeng, Y.Y.; Liao, N.S.; Cai, Z.X.; Liu, G. Lipid-micelles packaged with semiconducting polymer dots as simultaneous MRI / photoacoustic imaging and photodynamic / photo-thermal dual-modal therapeutic agents for liver cancer. J. Mater. Chem. B 2016, 4, 589-599. [CrossRef]

29. Wu, C.; Chiu, D.T. Highly fluorescent semiconducting polymer dots for biology and medicine. Angew. Chem. 2013, 52, 3086-3109. [CrossRef] [PubMed]

30. Massey, M.; Wu, M.; Conroy, E.M.; Algar, W.R. Mind your P's and Q's: the coming of age of semiconducting polymer dots and semiconductor quantum dots in biological applications. Curr. Opin. Biotechnol. 2015, 34, 30-40. [CrossRef] [PubMed]

31. Wei, H.; Li, B.; Li, J.; Wang, E.; Dong, S. Simple and sensitive aptamer-based colorimetric sensing of protein using unmodified gold nanoparticle probes. Chem. Commun. 2007, 36, 3735-3737. [CrossRef] [PubMed]

32. Che, W.I.; Bo, Y.J.; Mao, Y.F.; Yu, R.; Elena, G.M.; Bryant, F.J.; Yong, S.Z.; Chan, M.H.; Wei, S.; Zhou, X.H.; et al. Squaraine-Based Polymer Dots with Narrow, Bright Near-Infrared Fluorescence for Biological Applications. J. Am. Chem. Soc. 2015, 137, 173-178.

33. Chan, Y.H.; Wu, P.J. Semiconducting Polymer Nanoparticles as Fluorescent Probes for Biological Imaging and Sensing. Part. Part. Syst. Charact. 2015, 32, 11-28. [CrossRef]

34. Wan, Y.; Zheng, L.B.; Suna, Y.; Zhang, D. Multifunctional semiconducting polymer dots for imaging, detection, and photo-killing of bacteria. J. Mater. Chem. B 2014, 2, 4818-4825. [CrossRef]

35. Wu, C.F.; Jin, Y.H.; Schneider, T.; Burnham, D.R.; Smith, P.B.; Chiu, D.T. Ultra bright and bioorthogonal labeling of cellular targets using semiconducting polymer dots and click chemistry. Angew. Chem. Int. Ed. 2010, 49, 9436-9440. [CrossRef] [PubMed]

36. Wu, C.F.; Schneider, T.; Zeigler, M.; Yu, J.B.; Schiro, P.G.; Burnham, D.R.; McNeill, J.D.; Chiu, D.T. Bioconjugation of ultrabright semiconducting polymer dots for specific cellular targeting. J. Am. Chem. Soc. 2010, 132, 15410-15417. [CrossRef] [PubMed]

37. Yang, W.; Zhang, G.Y.; Weng, W.; Qiu, B.; Guo, L.H.; Lin, Z.H.; Chen, G.N. Signal on fluorescence biosensor for MMP-2 based on FRET between semiconducting polymer dots and a metal organic framework. RSC Adv. 2014, 4, 58852-58857. [CrossRef]

38. Zhu, S.; Liu, Z.; Hu, L.; Yuan, Y.; Xu, G. Turn-On Fluorescence Sensor Based on Single-Walled-Carbon-Nanohorn-Peptide Complex for the Detection of Thrombin. Chem. Eur. J. 2012, 18, 16556-16561. [CrossRef] [PubMed]

39. Jie, G.; Yuan, J. Novel Magnetic Fe3O4@CdSe Composite Quantum Dot-Based Electrochemiluminescence Detection of Thrombin by a Multiple DNA Cycle Amplification Strategy. Anal. Chem. 2012, 84, 2811-2817. [CrossRef] [PubMed]

40. Centi, S.; Tombelli, S.; Minunni, M.; Mascini, M. Aptamer-Based Detection of Plasma Proteins by an Electrochemical Assay Coupled to Magnetic Beads. Anal. Chem. 2007, 79, 1466-1473. [CrossRef] [PubMed] 
41. Liu, J.; Li, J.; Jiang, Y.; Yang, S.; Tan, W.; Yang, R. Combination of $\pi-\pi$ stacking and electrostatic repulsion between carboxylic carbon nanoparticles and fluorescent oligonucleotides for rapid and sensitive detection of thrombin. Chem. Commun. 2011, 47, 11321-11323. [CrossRef] [PubMed]

42. Wang, Y.; Bao, L.; Liu, Z.; Pang, D. Aptamer biosensor based on fluorescence resonance energy transfer from upconverting phosphors to carbon nanoparticles for thrombin detection in human plasma. Anal. Chem. 2011, 83, 8130-8137. [CrossRef] [PubMed]

43. Chang, H.; Tang, L.; Wang, Y.; Jiang, J.; Li, J. Graphene Fluorescence Resonance Energy Transfer Aptasensor for the Thrombin Detection. Anal. Chem. 2010, 82, 2341-2346. [CrossRef] [PubMed]

44. Yan, F.; Wang, F.; Chen, Z. Aptamer-based electrochemical biosensor for label-free voltammetric detection of thrombin and adenosine. Sens. Actuators B 2011, 160, 1380-1385. [CrossRef]

45. Kim, D.K.; Kerman, K.; Hiep, H.M.; Saito, M.; Yamamura, S.; Takamura, Y.; Kwon, Y.S.; Tamiya, E. Label-free optical detection of aptamer-protein interactions using gold-capped oxide nanostructures. Anal. Biochem. 2008, 379, 1-7. [CrossRef] [PubMed]

46. Yan, S.; Huang, R.; Zhou, Y.; Zhang, M.; Deng, M.; Wang, X.; Weng, X.; Zhou, X. Aptamer-based turn-on fluorescent four-branched quaternary ammonium pyrazine probe for selective thrombin detection. Chem. Commun. 2011, 47, 1273-1275. [CrossRef] [PubMed]

(C) 2018 by the authors. Licensee MDPI, Basel, Switzerland. This article is an open access article distributed under the terms and conditions of the Creative Commons Attribution (CC BY) license (http:/ / creativecommons.org/licenses/by/4.0/). 